\title{
Weak mixing in Lake Kivu: New insights indicate increasing risk of uncontrolled gas eruption
}

\author{
Martin Schmid \\ EAWAG, Limnological Research Center, Seestrasse 79, 6047 Kastanienbaum, Switzerland (martin.schmid@eawag.ch)
}

Michel Halbwachs

Université de Savoie, BP 1104, Savoie Technolac, 73376 Le Bourget du Lac Cedex, France

Bernhard Wehrli and Alfred Wüest

EAWAG, Limnological Research Center, Seestrasse 79, 6047 Kastanienbaum, Switzerland

[1] The deep waters of the East African Rift Lake Kivu contain large amounts of dissolved carbon dioxide and methane. The release of a fraction of these gases, which could be triggered by a magma eruption within the lake, would have catastrophic consequences for the two million people living on its shore. Up to now the safety assessment of the lake was based on the assumption that the gas concentrations in the deep waters are in a steady state with a residence time of 400 years. Turbulent transport was regarded as the main pathway of vertical exchange. Recent measurements and the analysis of the vertical transport processes in the lake radically change this evaluation. The vertical turbulent exchange is negligible, as documented by a spectacular set of several hundred double-diffusive layers. Gases are mainly transported out of the deep zones by a slow upwelling with a residence time of $800-1000$ years. Our results indicate that the methane production within the sediment has recently increased, leading to a gas accumulation in the deep waters and consequently decreasing the heat input needed to trigger a devastating gas release. With the estimated current $\mathrm{CH}_{4}$ production, the gas concentrations could approach saturation within this century.

Components: 5787 words, 5 figures, 2 tables.

Keywords: carbon dioxide; double diffusion; gas release; Lake Kivu; methane; mixing processes.

Index Terms: 4239 Oceanography: General: Limnology (0458, 1845, 4942); 4806 Oceanography: Biological and Chemical: Carbon cycling (0428)

Received 2 December 2004; Revised 30 April 2005; Accepted 6 May 2005; Published 26 July 2005.

Schmid, M., M. Halbwachs, B. Wehrli, and A. Wüest (2005), Weak mixing in Lake Kivu: New insights indicate increasing risk of uncontrolled gas eruption, Geochem. Geophys. Geosyst., 6, Q07009, doi:10.1029/2004GC000892.

\section{Introduction}

[2] Lake Kivu is an East African rift lake between Rwanda and the Democratic Republic of Congo (Figure 1) with maximum depth of $485 \mathrm{~m}$ and a volume of $550 \mathrm{~km}^{3}$. Seasonal mixing reaches only a depth of $50-80 \mathrm{~m}$. Below, about $300 \mathrm{~km}^{3}$ STP (gas volume at $0^{\circ} \mathrm{C}$ and 1 atm) carbon dioxide $\left(\mathrm{CO}_{2}\right)$ and $60 \mathrm{~km}^{3}$ STP methane $\left(\mathrm{CH}_{4}\right)$ are dissolved in the permanently stratified deep waters. $\mathrm{CH}_{4}$ concentrations are approximately $21 \%$ of $\mathrm{CO}_{2}$, but because of the low solubility of $\mathrm{CH}_{4}$, its contribution to the total gas pressure exceeds that of $\mathrm{CO}_{2}$ [Tietze, 1978; Schmid et al., 2004b]. Consequently, a gas release from Lake Kivu would be triggered by supersaturation of $\mathrm{CH}_{4}$, while $\mathrm{CO}_{2}$ would be stripped into the gas bubbles and contribute most to the released gas volume. Although the lake is currently in a relatively safe state, a gas release 


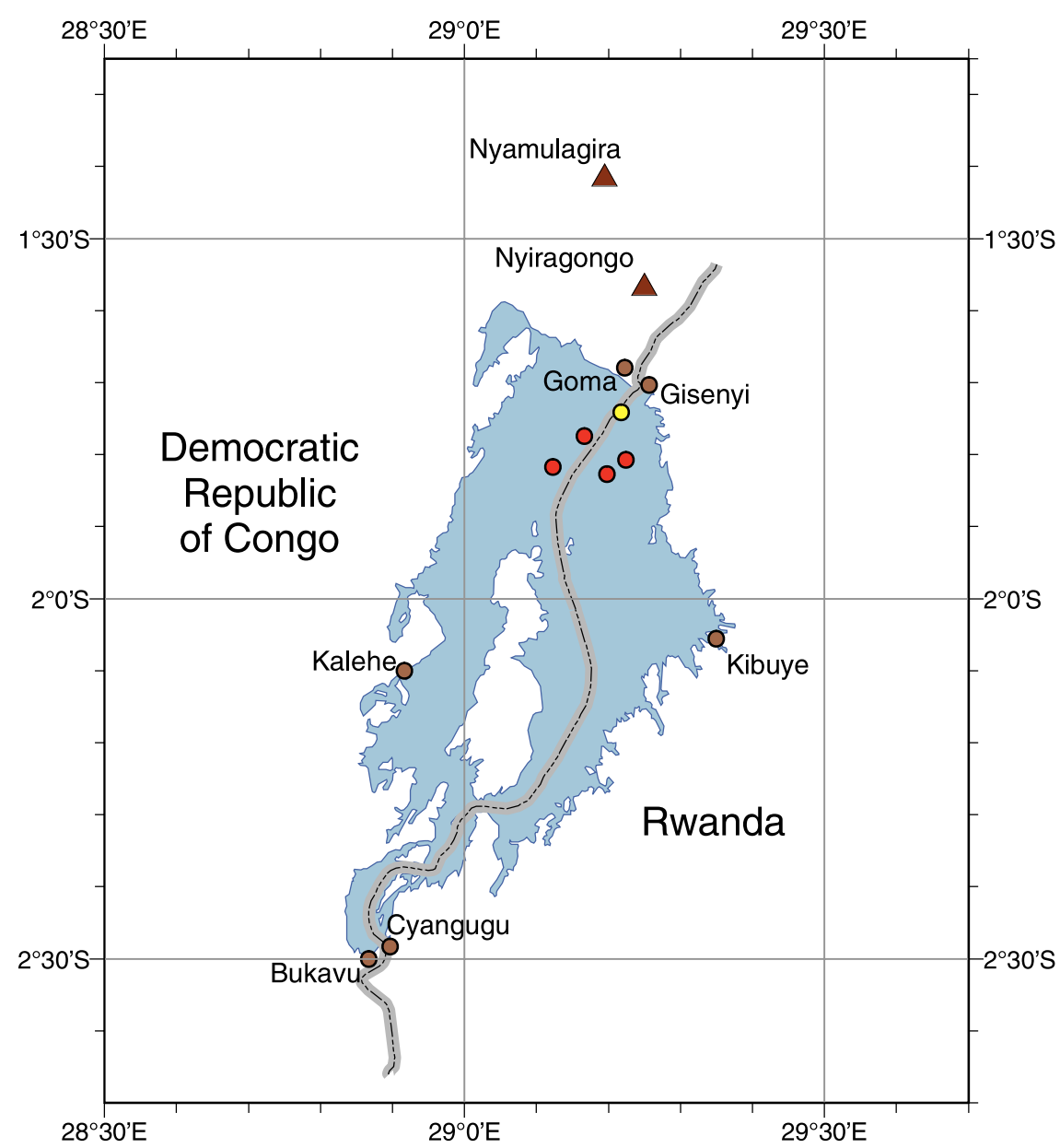

Figure 1. Map of Lake Kivu. The red circles show the locations of the four CTD profiles, and the yellow circle marks the location where water samples for chemical analysis were taken.

could be initiated by a sufficiently large volcanic eruption within the deep water [Schmid et al., 2004b]. On the basis of the sediment stratigraphy it has been suggested that a gas release had indeed happened before [Haberyan and Hecky, 1987]. Two active volcanoes are situated near the northern shore, Nyiragongo which erupted in January 1977 [Durieux, 2004] and January 2002 [Komorowski et al., 2004] and Nyamulagira which erupts every few years [Tedesco, 2004]. New fractures toward the lake opened during the last eruption of Nyiragongo, and the tectonic activity has been unusually high during the past few years [Komorowski et al., 2004]. Due to its large size and the high population density, a gas release from Lake Kivu could cause an unimaginable disaster, far beyond the events at the "Killer Lakes" Monoun in 1984 [Sigurdsson et al., 1987] and Nyos in 1986 [Kling et al., 1987; Sigvaldason, 1989] which claimed 37 and more than 1700 lives, respectively. These lakes are now artificially degassed [Halbwachs et al., 2004; Krajick, 2003].

[3] Bacteria produce $\mathrm{CH}_{4}$ in the lake sediment both by decomposing settled organic material and using magmatic $\mathrm{CO}_{2}$ and hydrogen [Deuser et al., 1973; Schoell et al., 1988]. In the surface layer $\mathrm{CH}_{4}$ is oxidized using oxygen and sulfate as electron acceptors. Two transport mechanisms bring the $\mathrm{CH}_{4}$ to the surface: (1) a deep water input leads to a slow upwelling over the whole lake area which transports $\mathrm{CH}_{4}$ upward, and (2) turbulent mixing causes a down-gradient transport of $\mathrm{CH}_{4}$. It has previously been assumed that the gases are mainly transported to the surface by turbulent diffusion with a residence time of 400 years in the deep water [Tietze, 1978]. In the following we will revise this picture of the vertical transport processes by first quantifying 


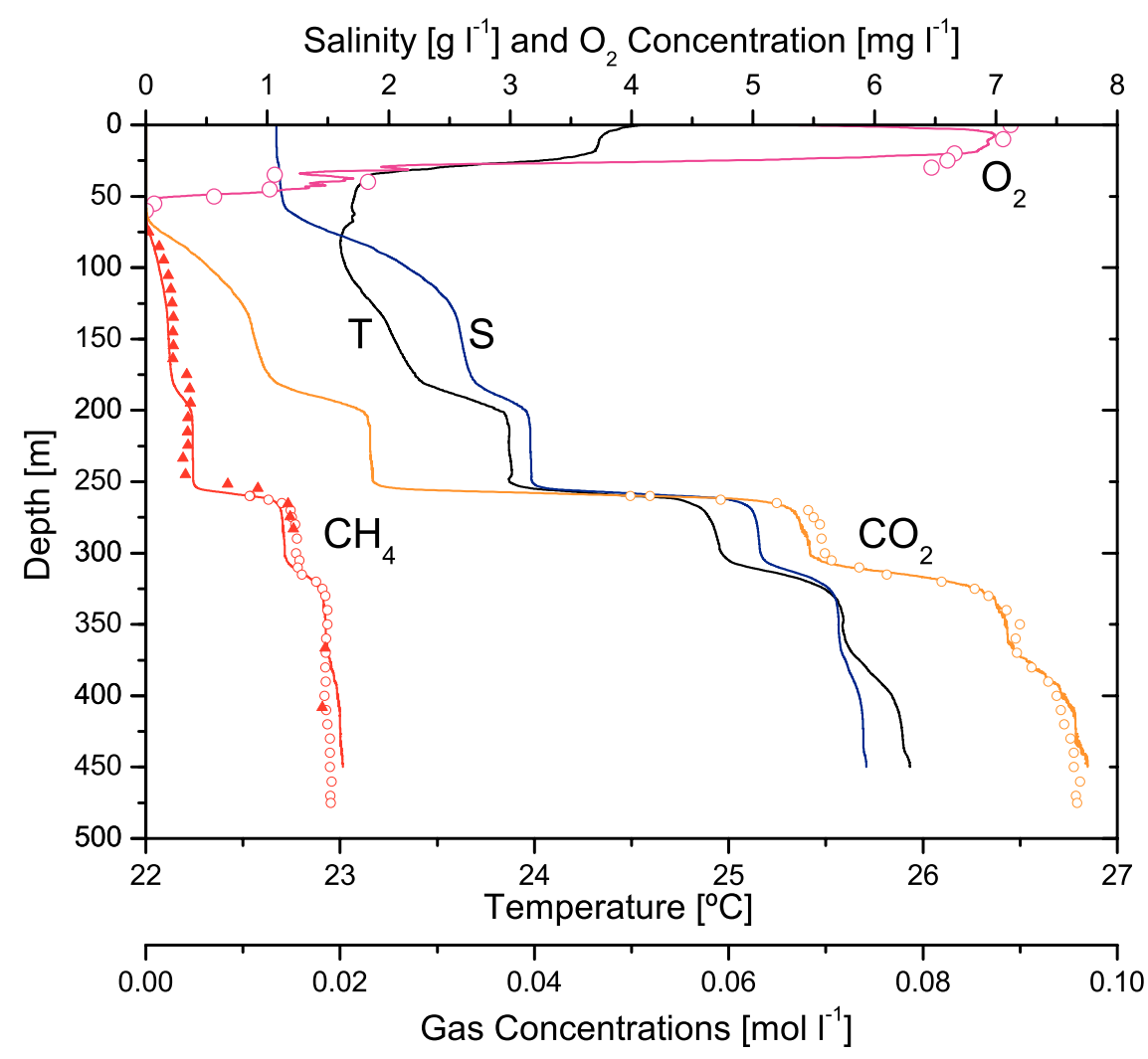

Figure 2. Vertical profiles of temperature $(\mathrm{T})$, salinity $(\mathrm{S})$, and dissolved gas concentrations in Lake Kivu in February 2004. The orange line is the $\mathrm{CO}_{2}$ concentration calculated from $\mathrm{pH}$ and alkalinity, the red line is the $\mathrm{CH}_{4}$ concentration assuming a constant $\mathrm{CH}_{4} / \mathrm{CO}_{2}$ ratio, the open circles show the gas concentrations measured in November 2003, and the triangles show the $\mathrm{CH}_{4}$ concentrations measured with the Capsum Mets sensor. The oxygen concentrations measured with the CTD probe and using the Winkler method are shown by the magenta line and the magenta circles, respectively.

the turbulent exchange and then the upwelling transport of $\mathrm{CH}_{4}$.

\section{Measurement Methods}

\subsection{CTD Profiles}

[4] Thirteen vertical profiles of temperature and conductivity (CTD) were measured in the northern half of Lake Kivu with a Sea-Bird SBE-19 which was equipped with a Sea-Bird SBE-22B combined $\mathrm{pH}$ and oxygen sensor. With the exception of a signature at $250 \mathrm{~m}$ depth (see below), temperature and salinity in the deep water were horizontally practically homogeneous. The four deepest reaching profiles were averaged to produce the temperature and salinity profiles in Figure 2.

\subsection{Temperature Microstructure Profiles}

[5] Ten vertical profiles of temperature microstructure were measured with a free-falling Sea-Bird
SBE 11 equipped with two Thermometrics FP07 microstructure thermistors with nominal response times of $7 \mathrm{~ms}$ and a pressure sensor to determine the sinking rate. The profiler sinking rate of $\sim 0.1 \mathrm{~m} \mathrm{~s}^{-1}$ and the sampling frequency of $96 \mathrm{~Hz}$ resulted in a vertical resolution of $\sim 1 \mathrm{~mm}$. The temperature resolution (a few $10^{-5}{ }^{\circ} \mathrm{C}$ ) of the microstructure probe was sufficient to resolve the temperature variance within the double-diffusive mixed layers (Figure 3).

\subsection{Water Chemistry}

[6] Water samples (Table 2) were analyzed with standard methods for alkalinity, nutrient contents and main ionic composition. Salinity was calculated from conductivity and ionic composition [Wüest et al., 1996] and agreed within $2 \%$ with the values calculated from measured ion concentrations. Historic conductivity and salinity values are inconsistent: The levels measured by Tietze [1978] in the deep water were about $10 \%$ higher than our values, 


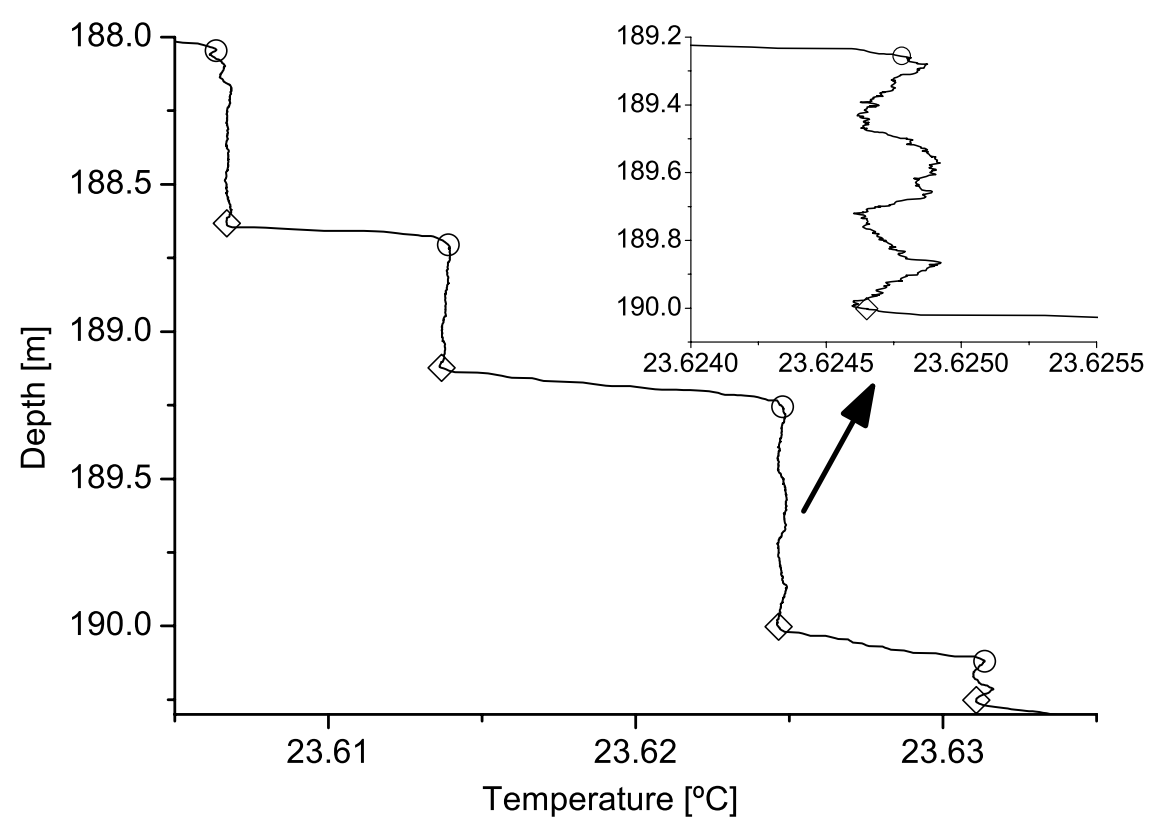

Figure 3. An example of double-diffusive layering observed in Lake Kivu at 188 to $190 \mathrm{~m}$ depth. The microstructure profiles were split into well-mixed layers and interfaces as depicted by the open circles (upper boundaries of mixed layers) and diamonds (lower boundaries of mixed layers). The sharpness of the transition between layers evidences the current activity of the double-diffusion. The inset shows the observed temperature variability within one of the mixed layers.

whereas those of Degens et al. [1973] were lower by almost a factor of two. However, recalculating conductivity from the main ionic composition given by Degens et al. [1973] yields values comparable to ours. $\mathrm{CO}_{2}$ was calculated from $\mathrm{pH}$ and alkalinity, including the effects of temperature and salinity on the first dissociation constant of $\mathrm{H}_{2} \mathrm{CO}_{3}$ [Cai and Wang, 1998]. The uncertainty in this calculation is mainly due to the $\mathrm{pH}$, since an error in $\mathrm{pH}$ of \pm 0.05 produces an error in the $\mathrm{CO}_{2}$ concentrations of approximately $\pm 10 \% . \mathrm{CH}_{4}$ was measured with a Capsum Mets methane sensor, which was calibrated for the high concentrations in Lake Kivu. The standard deviation observed by the manufacturer in the calibration was $0.4 \mathrm{mmol} \mathrm{L}^{-1}$. In the deep water of Lake Kivu this corresponds to an error of $2-5 \%$. The sensor recorded the $\mathrm{CH}_{4}$ concentration every 0.5 second. In the field, it exhibited an unexpectedly slow response time of $46 \mathrm{~min}$. The measured concentrations were extrapolated by fitting time series of 200 to 600 consecutive samples to an exponential curve. The error due to the fitting procedure was $0.5 \%$ below the chemocline at $270 \mathrm{~m}$ depth, $2-3 \%$ within the chemocline and up to $10 \%$ above $230 \mathrm{~m}$ depth. It was larger at lower concentrations due to the higher relative noise of the instrument at low voltages.

[7] In November 2003, $\mathrm{CH}_{4}$ and $\mathrm{CO}_{2}$ concentrations had been measured by transferring water through a polyethylene tube to the lake surface, separating the gas and water phases, measuring their flow rates, and determining the $\mathrm{CH}_{4}$ and $\mathrm{CO}_{2}$ concentrations in the gas phase with a portable GA2000 infrared gas analyzer. The gas analyzer was tested by measuring gas samples from the lake with another identical instrument and before and after the expedition with a standard of $40 \% \mathrm{CH}_{4}$ and $60 \% \mathrm{CO}_{2}$. Errors were in the range of $\pm 0.2 \%$ volume, i.e., less than $2 \%$ of $\mathrm{CH}_{4}$ concentrations observed in the lake. The measurement error for the Schlumberger gas flowmeter is about $\pm 2 \%$, while the error of the water flow can be neglected. Consequently, a total error of $\pm 4 \%$ is assumed. Measured ratios of $\mathrm{CH}_{4}$ to $\mathrm{CO}_{2}$ concentrations ranged between 0.196 and 0.224 . For the analysis of the double-diffusive transport, where the effect of $\mathrm{CH}_{4}$ is negligible compared to salinity and $\mathrm{CO}_{2}$, $\mathrm{CH}_{4}$ was assumed to be a constant fraction of $\mathrm{CO}_{2}$ (Figure 2).

\subsection{Temperature Time Series}

[8] Four Vemco minilog temperature loggers which recorded temperature every 15 min with a resolution of $0.01^{\circ} \mathrm{C}$ were installed in November 2003 at depths of 15,185, 260 and $315 \mathrm{~m}$ and retrieved in February 2004. From this time series and the background temperature gradient, vertical displacements due to internal waves and conse- 
quently their energy content was determined with the same method as for Lake Nyos [Schmid et al., 2004a].

\section{Results and Discussion of Measurements}

[9] Average vertical profiles of temperature and salinity, as well as $\mathrm{CO}_{2}$ and $\mathrm{CH}_{4}$ concentrations in February 2004 are shown in Figure 2. Compared to previous measurements in the 1970s [Tietze, 1978], the measured $\mathrm{CH}_{4}$ concentrations in the deep water have increased by $15-20 \%$ and $\mathrm{CO}_{2}$ concentrations by about $10 \%$. The increase in the $\mathrm{CH}_{4}$ concentrations is clearly significant if we exclude a systematic error of much more than $5 \%$ in the measurements of Tietze, while the observed $10 \%$ change in $\mathrm{CO}_{2}$ indicates an augmentation but is hardly sufficient to refute the null hypothesis of unaltered concentrations.

[10] Below the zone reached by seasonal mixing, temperature, salinity, $\mathrm{CO}_{2}$ and $\mathrm{CH}_{4}$ all increase with depth. Salinity and $\mathrm{CO}_{2}$ are stabilizing the water column, whereas temperature and $\mathrm{CH}_{4}$ are destabilizing (dissolved $\mathrm{CH}_{4}$ decreases the water density). Since the molecular thermal diffusivity is about 2 orders of magnitude larger than that of dissolved substances, the destabilizing effect of temperature can lead to the formation of mixed layers by double-diffusive convection [Turner, 1973]. In fact, our temperature microstructure profiles show 250-350 well-mixed layers between 120 and $460 \mathrm{~m}$ depth. Most of these layers are between 0.2 and $1.0 \mathrm{~m}$ thick, with interfaces as thin as $0.05-0.4 \mathrm{~m}$ and temperature steps between 0.001 and $0.005^{\circ} \mathrm{C}$. A typical example of four successive layers is shown in Figure 3. Generally the interfaces were free of temperature inversions, indicating complete absence of any vertical turbulence. Consequently, below $120 \mathrm{~m}$ depth, double-diffusive convection must be dominating over the background turbulent diffusivity and we can neglect the latter in our analysis.

[11] The intensity of double-diffusive convection is characterized by the density ratio $\mathrm{R}_{\rho}=\beta(\partial \mathrm{S} / \partial \mathrm{z}) /$ $\alpha(\partial \mathrm{T} / \partial \mathrm{z})$, the ratio between the stabilizing density effect of the salinity (S) gradient and the destabilizing effect of the temperature $(\mathrm{T})$ gradient [Turner, 1973]. Here, $\alpha$ is the thermal expansivity and $\beta$ the coefficient of haline contraction. In the case of Lake Kivu, gas concentration gradients multiplied by their contraction coefficients have to be added to the numerator [Schmid et al., 2004a]. Below $150 \mathrm{~m}$ depth, $\mathrm{R}_{\rho}$ ranges between 2 and 4 . The ratio of the apparent diffusivity of dissolved substances to that of heat decreases with increasing $\mathrm{R}_{\rho}$ [Kelley, 1990; Turner, 1965].

[12] The heat fluxes through the double-diffusive steps were calculated with three different methods: (1) from the interface temperature gradients between convective layers assuming molecular diffusion with a diffusion coefficient of 1.4 . $10^{-7} \mathrm{~m}^{2} \mathrm{~s}^{-1}$, (2) using the semiempirical flux law for double-diffusion by Kelley [1990], which successfully predicted heat fluxes in the comparable case of Lake Nyos [Schmid et al., 2004a], and (3) from observed temperature fluctuations within convectively mixed layers by applying the convective scaling relation and assuming that dissipation within a layer is equal to the buoyancy flux [Matzner, 2001].

[13] Figure 4 shows the results of methods 1 and 2 . Method 3 yielded similar results as method 2 but with a larger scatter. Method 1 was expected to underestimate the heat fluxes since there is some additional heat transport through the interfaces besides molecular diffusion due to intrusions of rising and sinking double-diffusive convective plumes. Except for the regions near the high gradient zones, and for the zone between 180 and $200 \mathrm{~m}$ depth, the heat fluxes determined by method 2 are only on the order of $0.01-0.04 \mathrm{~W} \mathrm{~m}^{-2}$, which is below typical heat fluxes observed in East Africa [Pollack et al., 1993] but within the large range of $0.016-0.18 \mathrm{~W} \mathrm{~m}^{-2}$ measured in the sediment of Lake Kivu [Degens et al., 1973]. The corresponding $\mathrm{CH}_{4}$ flux through the chemocline at $260 \mathrm{~m}$ depth, calculated with the flux laws of Kelley [1990] as described by Schmid et al. [2004a], is only on the order of $1 \mathrm{~g} \mathrm{CH}_{4}-\mathrm{C} \mathrm{m}^{-2} \mathrm{yr}^{-1}$, indicating a residence time of $\mathrm{CH}_{4}$ in the deep water of $\sim 20,000$ years. It will be shown below that the true residence time is much smaller due to the upwelling transport. The double-diffusive fluxes are enhanced near the gradient zones (Figure 4) because the high gradients are sustained by lateral water inputs (see below) while double-diffusive convection tends to smooth out the large-scale gradients.

[14] A previous analysis of double-diffusive steps in Lake Kivu [Newman, 1976] yielded much higher heat fluxes of $0.7-1.6 \mathrm{~W} \mathrm{~m}^{-2}$. These calculations were biased by an underestimation of the salinity gradient of at least a factor of 2 , overestimating the 


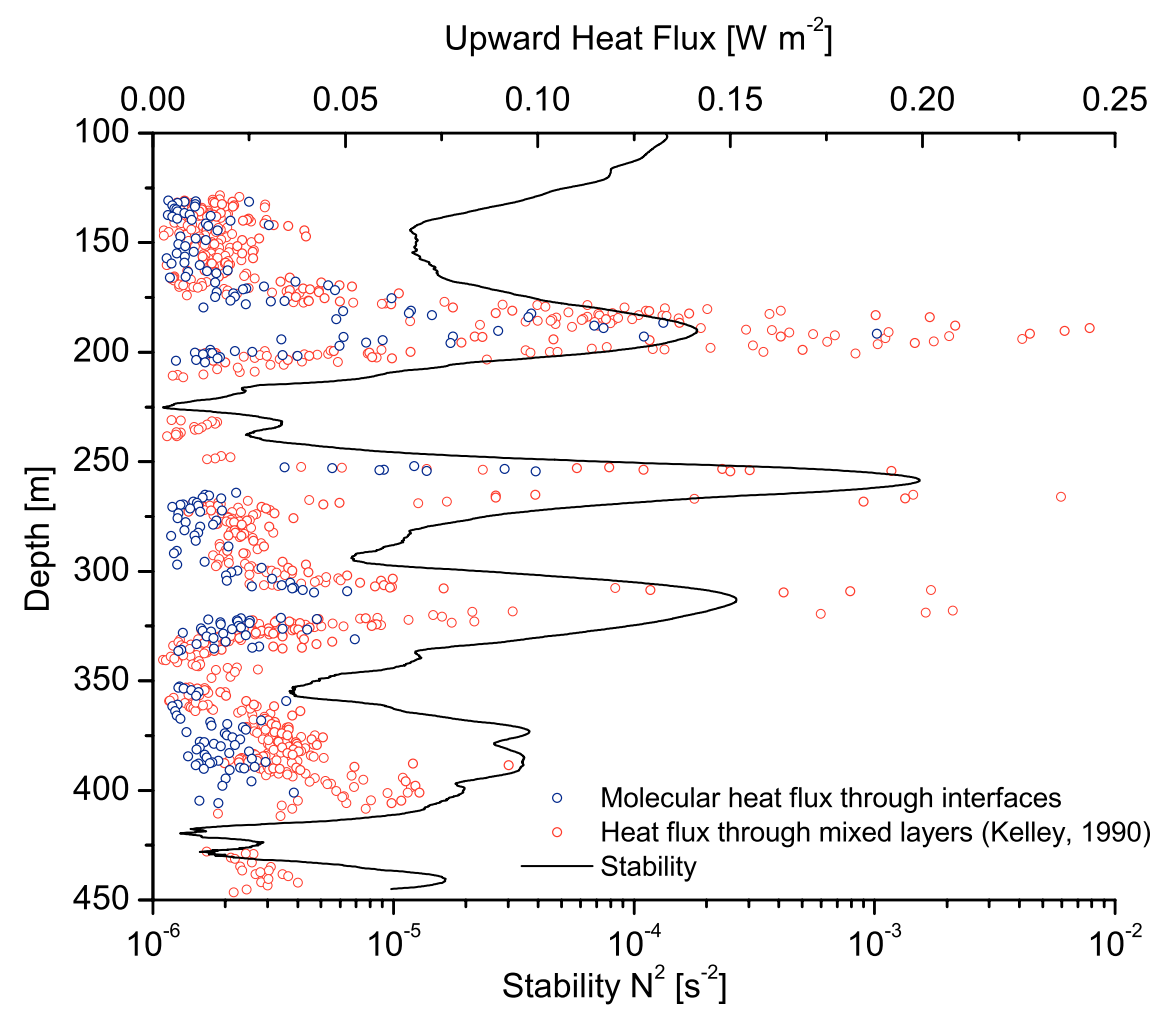

Figure 4. Vertical upward heat fluxes calculated from the structure of the mixed layers using the semiempirical flux law of Kelley [1990] (red dots) and by assuming molecular diffusion within the interfaces (blue circles), and vertical profile of the stability $\mathrm{N}^{2}$.

heat fluxes by a factor of 4 . Nevertheless, the mixed layers observed by Newman [1976] were larger with an average thickness of $1.0 \mathrm{~m}$ and $0.02^{\circ} \mathrm{C}$ temperature steps, values that were reached by only $20 \%$ (layer thickness) and 3\% (temperature steps) of our observations. This indicates that double-diffusive convection was more intense in the 1970s. Since then, temperature has increased in the top $200 \mathrm{~m}$ of the lake by about $0.3-0.5^{\circ} \mathrm{C}$, most probably due to global warming [Lorke et $a l ., 2004$ ], weakening the average temperature gradient by about $15 \% . \mathrm{CO}_{2}$ concentrations seem to have increased by about $10 \%$ and $\mathrm{CH}_{4}$ concentrations by about $15-20 \%$ in the deep waters. In total, $\mathrm{R}_{\rho}$ has increased by about $20-30 \%$ within 30 years, weakening the upward transport of salts and gases.

\section{Model Description}

[15] A simple one-dimensional diffusive-advective model for salinity and $\mathrm{CH}_{4}$ was set up with the lake module of the software AQUASIM 2.1 [Reichert, 1994]. Simulations were performed with a $1-\mathrm{m}$ vertical grid and with variable time stepping chosen by the integration algorithm. Shortly, the following knowledge and assumptions about the system were implemented:

[16] There must be at least one source in the deep waters of the lake which compensates for the salt losses by the Ruzizi outflow [Degens et al., 1973]. The water input by this source displaces the ambient water causing a slow upwelling transport. The strong temperature gradient at $260 \mathrm{~m}$ depth with an increase of $0.7^{\circ} \mathrm{C}$ within $6 \mathrm{~m}$, which was observed by all measurements since Damas [1937], needs to be sustained by an active process. Otherwise it would be destroyed by molecular heat diffusion within a few years. A distinct negative temperature signal (and a weaker signal in conductivity) was observed at $250 \mathrm{~m}$ depth which was strongest in the profiles measured in the North-Eastern part of the lake and can only be explained by an input of cooler and less saline water at this depth. This input is most probably the process sustaining the strong temperature gradient below. Furthermore, the observed decrease in $\mathrm{CH}_{4}$ must be due to dilution with water containing little $\mathrm{CH}_{4}$ since oxidation can be excluded in the 
anoxic and sulphate-depleted deep water. No clear signals from water inputs were observed above the other strong gradients, but since there is no other explanation for these gradients, we assume that they are sustained by similar water inputs free of dissolved $\mathrm{CH}_{4}$. The flow rates, temperatures and salt concentrations of these inputs as well as the geothermal heat flux were fitted to reproduce the observed salinity and temperature profiles.

[17] Below $120 \mathrm{~m}$, turbulent vertical diffusivity was set to $0.15 \cdot \varepsilon / \mathrm{N}^{2}$ [Osborn, 1980] for temperature and, based on our analysis of the fluxes through the double-diffusive layers, a factor 10 lower for salt and gases. Here, $\mathrm{N}^{2}$ is the stability of the density stratification. The energy dissipation $\varepsilon$ below $120 \mathrm{~m}$ depth is on the order of $1.0 \cdot 10^{-10} \mathrm{~W} \mathrm{~kg}^{-1}$, which was confirmed by three independent methods: by analyzing Batchelor spectra of temperature microstructure measurements as described by Kocsis et al. [1999], by applying scaling relations to the observed double-diffusive staircase, and by estimating the energy content of vertical displacements due to internal waves observed with temperature loggers. No double-diffusive layers were observed above $120 \mathrm{~m}$ depth, and the temperature minimum at $85 \mathrm{~m}$ indicates occasional convective mixing down to this depth. The top $50 \mathrm{~m}$ of the lake are mixed annually. Consequently, diffusivity was steadily increased from $120 \mathrm{~m}$ depth to $10^{-5} \mathrm{~m}^{2} \mathrm{~s}^{-1}$ at $50 \mathrm{~m}$ depth and kept constant above.

[18] A fast process removing $\mathrm{CH}_{4}$ by oxidation above $60 \mathrm{~m}$ depth was introduced into the model. $\mathrm{CH}_{4}$ production was assumed to be homogeneous at the sediment surface; i.e., the $\mathrm{CH}_{4}$ input is proportional to the sediment surface area at each depth. It was assumed that the historic value of $\mathrm{CH}_{4}$ production had been constant for a sufficiently long time to approach equilibrium (in our model we arbitrarily used 930 years, but the exact value has no significant influence on the results), that it started to increase linearly with time with the growing population 30 years before the 1974 measurements and increased even more between 1974 and 2004. The three values of $\mathrm{CH}_{4}$ production (historic, 1974 and 2004) were determined by fitting to the $\mathrm{CH}_{4}$ profiles observed in 1974 [Tietze, 1978] and 2004. Of course the chosen temporal development is one of several reasonable possibilities, but using another time frame would not alter the average $\mathrm{CH}_{4}$ production needed to produce the observed increase in concentrations between 1974 and 2004.

\section{Results and Discussion of Simulations}

[19] Figure 5 compares simulated and observed temperatures, salt and $\mathrm{CH}_{4}$ concentrations. All observations were reproduced with high accuracy except for surface temperatures, which are influenced by seasonal surface heat fluxes not included in the model. Table 1 shows the water sources and their properties as used in the model to optimally reproduce the observations. The observed largescale temperature profile could be best predicted with a geothermal heat flux of $0.02 \mathrm{~W} \mathrm{~m}^{-2}$ which agrees well with the independent estimates of small-scale double-diffusive heat fluxes (Figure 3).

[20] The total simulated water input below the surface layer is $1.3 \mathrm{~km}^{3} \mathrm{yr}^{-1}$, which is $40 \%$ of the Ruzizi outflow [Degens et al., 1973]. The absolute flow rates of the sources given in Table 1 cannot be exactly determined, but to produce the observed steps, it is absolutely necessary that the inputs at 180 and $250 \mathrm{~m}$ depth are about one order of magnitude larger than those below. The fact that both deuterium and ${ }^{18} \mathrm{O}$ isotopes lie on straight mixing lines with conductivity [Tietze, 1978], indicates that the water within the lake is a blend of only one groundwater source and lake surface water, implying that also the mid-depth source water consists of the same two end-members. This could be caused by either lake surface water infiltrating into the groundwater system, or by groundwater entering the lake above $100 \mathrm{~m}$ depth and being diluted with lake water while sinking down to its intrusion depth just above a high density gradient. In the second case, the sources should already contain some $\mathrm{CH}_{4}$ from the lake water which would require slight changes in the properties of the mid-depth sources.

[21] The calculated residence time for the water below $260 \mathrm{~m}$ depth is $\sim 870$ years, with an upward $\mathrm{CH}_{4}$ transport on the order of $\sim 30 \mathrm{~g} \mathrm{C} \mathrm{m}^{-2} \mathrm{yr}^{-1}$. From this analysis we conclude that the water body below the chemocline at $260 \mathrm{~m}$ depth is more strongly decoupled from the upper part of the lake than previous budget calculations assumed. This means that there is more time available for $\mathrm{CH}_{4}$ to accumulate in the deep water.

[22] The $\mathrm{CH}_{4}$ production needed to fit the observed profiles was a constant historic production of $32 \mathrm{~g}$ 


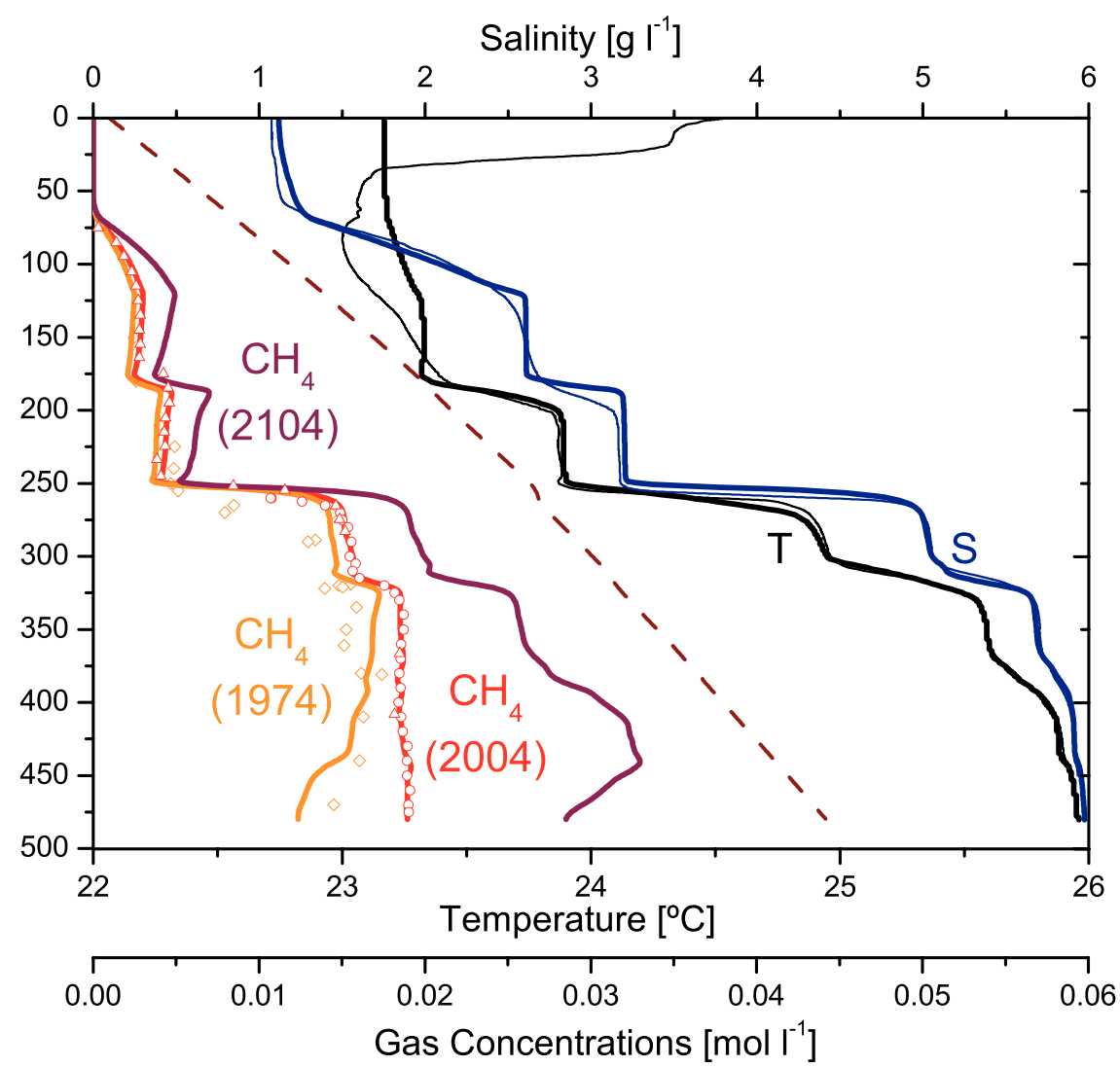

Figure 5. Simulated (thick lines) $\mathrm{CH}_{4}$ concentrations, temperatures $(\mathrm{T})$, and salinities $(\mathrm{S})$ compared to measurements (thin lines and symbols), and simulated $\mathrm{CH}_{4}$ concentration in 100 years compared to $80 \% \mathrm{CH}_{4}$ saturation (dashed line).

$\mathrm{CH}_{4}-\mathrm{C} \mathrm{m} \mathrm{m}^{-2} \mathrm{yr}^{-1}$, rising to values of 70 in 1974 and 120 in 2004 . The development of $\mathrm{CH}_{4}$ production could have been different, but an average of about $100 \mathrm{~g} \mathrm{CH}_{4}-\mathrm{C} \mathrm{m}^{-2} \mathrm{yr}^{-1}$ in the past 30 years is needed to reproduce the observed $\mathrm{CH}_{4}$ concentrations. Even if we conservatively assume a growth in $\mathrm{CH}_{4}$ concentrations of only $10 \%$, the recent production would still be at least twice the historic value. The historic production agrees with the oxidation rate of $30 \mathrm{~g} \mathrm{CH}_{4}-\mathrm{C} \mathrm{m}^{-2} \mathrm{yr}^{-1}$ at the oxic/anoxic interface at 35 to $50 \mathrm{~m}$ depth observed in 1971 [Jannasch, 1975]. Because of the high residence time of $\mathrm{CH}_{4}$, the recent production would not yet have had a large influence on this oxidation rate. Most probably the present structure took longer to evolve than the 990 years simulated, as weaker stratification would have facilitated turbulent upward transport in earlier times. Altogether the simulated time frame is consistent with the theory based on observations in the lake sediment stratigraphy that the present stable stratification was set up about 2000 years ago [Stoffers and Hecky, 1978; Haberyan and Hecky, 1987].

[23] Primary production within Lake Kivu was estimated at $375 \mathrm{~g} \mathrm{C} \mathrm{m}^{-2} \mathrm{yr}^{-1}$ in 1971 [Degens

Table 1. Input Sources Used in the One-Dimensional Diffusive-Advective Model of Lake Kivu

\begin{tabular}{ccccc}
\hline Depth, $\mathrm{m}$ & Depth Range, $\mathrm{m}$ & Flow, $\mathrm{m}^{3} \mathrm{~s}^{-1}\left(\mathrm{~km}^{3} \mathrm{yr}^{-1}\right)$ & Salinity, $\mathrm{g} \mathrm{l}^{-1}$ & Temperature, ${ }^{\circ} \mathrm{C}$ \\
\hline 180 & 10 & $22(0.69)$ & 2.1 & 22.7 \\
250 & 5 & $15(0.47)$ & 2.7 & 23.3 \\
315 & 10 & $1(0.03)$ & 3.4 & 25.2 \\
365 & 50 & $1.5(0.05)$ & 5.5 & 24.5 \\
425 & 60 & $0.8(0.03)$ & 5.8 & 25.3 \\
465 & 30 & $1.25(0.04)$ & 6.0 & 26.0 \\
\hline
\end{tabular}


Table 2. Alkalinity, pH, and Concentrations of Calcium, Sodium, Chloride, Silica, Phosphate, Ammonium, Hydrogen Sulfide, and Sulfate Measured in Water Samples From Lake Kivu in February 2004 ${ }^{\mathrm{a}}$

\begin{tabular}{|c|c|c|c|c|c|c|c|c|c|c|}
\hline Depth, m & Alk, mM & $\mathrm{pH}$ & $\mathrm{Ca}^{2+}, \mathrm{mM}$ & $\mathrm{Na}^{+}, \mathrm{mM}$ & $\mathrm{Cl}^{-}, \mathrm{mM}$ & $\mathrm{Si}, \mu \mathrm{M}$ & $\mathrm{PO}_{4}^{3-}, \mu \mathrm{M}$ & $\mathrm{NH}_{4}^{+}, \mu \mathrm{M}$ & $\mathrm{H}_{2} \mathrm{~S}, \mu \mathrm{M}$ & $\mathrm{SO}_{4}^{2-}, \mu \mathrm{M}$ \\
\hline $\begin{array}{l}0 \\
{[0]}\end{array}$ & 12.9 & 9.11 & $\begin{array}{c}0.10 \\
{[1.19]}\end{array}$ & $\begin{array}{c}4.30 \\
{[5.28]}\end{array}$ & 0.51 & [231] & $\begin{array}{c}0.37 \\
{[0.8]}\end{array}$ & $\begin{array}{c}0 \\
{[18]}\end{array}$ & 0 & 120 \\
\hline 10 & 12.8 & 9.11 & 0.10 & 4.27 & 0.50 & & 0.39 & 0 & 0 & 128 \\
\hline 20 & 12.8 & 9.11 & 0.10 & 4.33 & 0.49 & & 0.36 & 0 & 0 & 130 \\
\hline 30 & 12.8 & 8.97 & 0.10 & 4.30 & 0.50 & 133 & 0.39 & 0 & 0 & 128 \\
\hline 40 & 12.9 & 8.92 & 0.11 & 4.36 & 0.50 & 134 & 0.34 & 0 & 0 & 123 \\
\hline 50 & 13.0 & 8.86 & 0.13 & 4.41 & 0.54 & 138 & 0.37 & 0 & 0 & 127 \\
\hline 60 & 13.4 & 8.68 & 0.17 & 4.48 & 0.54 & 166 & 0.37 & 4 & 4 & 125 \\
\hline 70 & 15.5 & 7.74 & 0.37 & 4.86 & 0.66 & 229 & 4.74 & 126 & 101 & 83 \\
\hline 80 & 19.1 & 7.19 & 0.91 & 6.10 & 0.72 & 342 & 13.28 & 281 & 233 & 46 \\
\hline 90 & 23.1 & 7.00 & 1.27 & 7.19 & 0.82 & 481 & 23.97 & & 275 & 26 \\
\hline 100 & 25.9 & 6.90 & 1.57 & 7.56 & 0.90 & 564 & 29.45 & 578 & 292 & 23 \\
\hline [100] & & & [1.60] & [8.35] & & [424] & [18.8] & [487] & & \\
\hline 120 & 29.0 & 6.79 & 1.94 & 8.50 & 0.98 & 590 & 36.76 & 708 & 305 & 22 \\
\hline 140 & 30.4 & 6.74 & 1.98 & 8.46 & 1.02 & 630 & 41.26 & 810 & 356 & 18 \\
\hline 160 & 31.0 & 6.71 & 2.07 & 8.75 & 1.02 & 645 & 42.10 & 866 & & \\
\hline 180 & 31.5 & 6.67 & 1.99 & 8.64 & 1.06 & 657 & 42.52 & 1101 & & \\
\hline 200 & 37.2 & 6.49 & 2.27 & 9.93 & 1.33 & 810 & 60.80 & 1336 & & \\
\hline [200] & & & [2.07] & [10.64] & & [428] & [32.7] & [1314] & & \\
\hline 220 & 37.6 & 6.47 & 2.47 & 10.84 & 1.36 & 829 & 65.72 & 1373 & & \\
\hline 240 & 37.6 & 6.47 & 2.48 & 10.77 & 1.40 & 825 & 65.29 & 1367 & & \\
\hline 260 & 54.6 & 6.24 & 2.99 & 14.33 & 1.91 & 1196 & 128.44 & 2722 & & \\
\hline 280 & 60.5 & 6.16 & 3.35 & 17.00 & 1.96 & 1283 & 156.56 & 3361 & & \\
\hline 300 & 61.0 & 6.16 & 3.31 & 16.78 & 2.05 & 1286 & 158.67 & 3514 & & \\
\hline 320 & 66.9 & 6.10 & 3.46 & 18.89 & 2.07 & 1371 & 177.64 & 3696 & & \\
\hline 340 & 69.2 & 6.08 & 3.47 & 19.34 & 2.11 & 1413 & 181.86 & 4001 & & \\
\hline [350] & & & {$[2.77]$} & [20.24] & & [1056] & [53.2] & [5460] & & \\
\hline 380 & 69.5 & 6.07 & 3.36 & 18.91 & 2.24 & 1426 & 182.91 & 3909 & & \\
\hline 420 & 71.5 & 6.06 & 3.64 & 20.60 & 2.38 & 1613 & 183.91 & 3955 & & \\
\hline [450] & & & {$[2.81]$} & [21.20] & & [1226] & [54.8] & [7105] & & \\
\hline
\end{tabular}

${ }^{a}$ Alk, alkalinity. The values from Degens et al. [1973] are given in brackets for comparison.

et al., 1973]. The riparian population has at least doubled since then, and nutrient input to the lake and primary production should have risen significantly. A comparison of our chemical data with those of Degens et al. [1973] confirm the increased biological activity: Concentrations of silica (by $30-35 \%$ ), calcium (by 25-30\%) and phosphate (by more than a factor 3 ) all strongly increased in the deep waters and decreased in the surface waters (Table 2), indicating a higher export of organic material from the surface layer to the deep waters and a corresponding precipitation of calcite in the surface layer and its redissolution in the deep waters. It should be noted that the deep water ammonium $\left(\mathrm{NH}_{4}^{+}\right)$concentrations given by Degens et al. [1973] disagree with this interpretation, as they were almost a factor of two larger than ours. However, their $\mathrm{NH}_{4}^{+}$data did not match the mixing lines shown by all other constituents, whereas we observed a perfect correlation with phosphate with a N:P ratio of 21.5 .
[24] If we conservatively estimate the average primary production from 1974 to 2004 at $400 \mathrm{~g}$ $\mathrm{C} \mathrm{m}^{-2} \mathrm{yr}^{-1}, 25 \%$ of the produced $\mathrm{C}$ would have to be converted to $\mathrm{CH}_{4}$ at the sediment surface, assuming that all $\mathrm{CH}_{4}$ is biogenic [Schoell et al., 1988]. Another more speculative hypothesis for the increased export of organic matter to the deep waters is the introduction of the sardine Limnothrissa miodon to Lake Kivu in 1959. In Lake Kariba, the introduction of this species led to a drastic reduction of the zooplankton biomass and an increase in phytoplankton [Marshall, 1991]. Similar effects were observed in Lake Kivu [Dumont, 1986], even though in the meantime a new equilibrium seems to have been established [Isumbisho et al., 2004].

[25] The conclusion that diffusive transport is very weak and upward transport is dominated by upwelling with a deep water residence time of $800-$ 1000 years has several important consequences. 
We do not know whether the deep water input will be sustained constantly in the future. If this water input weakens, the accumulation of $\mathrm{CH}_{4}$ in the deep water will intensify. The residence time of dissolved gases in the deep water is longer than previously assumed, which implies that a larger part of an increasing $\mathrm{CH}_{4}$ production accumulates in the deep water and dangerous concentrations could be reached more quickly. Since $\mathrm{CH}_{4}$ is accumulating in the water during the upwelling, in a steady state condition the maximal concentrations would develop not in the deepest zones but just below the chemocline at $260 \mathrm{~m}$ depth where a lower concentration is needed to reach saturation.

[26] At the estimated current $\mathrm{CH}_{4}$ production, the gas concentrations in the deep waters of the lake would approach saturation within this century. Presently, $\mathrm{CH}_{4}$ causes $\sim 80 \%$ of the gas pressure. The $80 \%$ saturation line is shown for comparison in Figure 5. The probability of a gas release triggered by a magmatic eruption within the lake increases much faster than the $\mathrm{CH}_{4}$ concentration due to the nonlinear relation between gas concentrations and the heat input needed to produce a rising plume that reaches saturation depth [Schmid et al., 2004b]. Once the total gas pressure approaches the hydrostatic pressure, a magmatic eruption is no longer required, and a gas release might even be triggered by a strong internal wave. Considering the two million people at risk and the strong recent tectonic activity [Komorowski et al., 2004], we suggest that the gas concentrations in the lake should be critically monitored and possibly reduced by gas stripping techniques in the next decades.

\section{Acknowledgments}

[27] We thank our technicians M. Schurter, C. Dinkel, and J.-C. Tochon for their invaluable support during the preparation and the implementation of the measurements, B. Baluku, and the captains and crew of the Dakota for their assistance at field work, D. Rwigema and E. Nsanzumuganwa for local logistic support without which the expeditions would not have been possible, L. C. Yee for data preparation, and H. Peters, W. Aeschbach-Hertig, J. Varekamp, W.C. Evans, and an unknown reviewer for critically reviewing the manuscript. The field work was supported by the UN Office for the Coordination of Humanitarian Affairs (OCHA).

\section{References}

Cai, W.-J., and Y. Wang (1998), The chemistry, fluxes and sources of carbon dioxide in the estuarine waters of the
Satilla and Altamaha Rivers, Georgia, Limnol. Oceanogr., 43(4), 657-668.

Damas, H. (1937), La stratification thermique et chimique des lacs Kivu, Edourd et Ndalaga (Congo Belge), Verh. Int. Ver. Limnol., 8(3), 51-68.

Degens, E. T., R. P. von Herzen, H.-K. Wong, W. G. Deuser, and H. W. Jannasch (1973), Lake Kivu: Structure, chemistry and biology of an East African Rift Lake, Geol. Rundsch., 62, 245-277.

Deuser, W. G., E. T. Degens, and G. R. Harvey (1973), Methane in Lake Kivu: New data bearing its origin, Science, 181, 51-54.

Dumont, H. J. (1986), The Tanganyika Sardine in Lake Kivu: Another ecodisaster for Africa?, Environ. Conserv., 13, $143-148$.

Durieux, J. (2004), Nyiragongo: The January 10th 1977 eruption, Acta Vulcanol., 14/15, 145-148.

Haberyan, K. A., and R. E. Hecky (1987), The late Pleistocene and Holocene stratigraphy and paleolimnology of Lake Kivu and Tanganyika, Palaeogeogr. Palaeoclimatol. Palaeoecol., 61, 169-197.

Halbwachs, M., et al. (2004), Degassing the "Killer Lakes" Nyos and Monoun, Cameroon, Eos Trans. AGU, 85, 281288.

Isumbisho, M., M. Kaningini, J.-P. Descy, and E. Baras (2004), Seasonal and diel variations in diet of the young stages of the fish Limnothrissa miodon in Lake Kivu, Eastern Africa, J. Trop. Ecol., 20, 73-83.

Jannasch, H. W. (1975), Methane oxidation in Lake Kivu (central Africa), Limnol. Oceanogr., 20(5), 860-864.

Kelley, D. E. (1990), Fluxes through diffusive staircases: A new formulation, J. Geophys. Res., 95(C3), 33653371.

Kling, G. W., M. A. Clark, H. R. Compton, J. D. Devine, W. C. Evans, A. M. Humphrey, E. J. Koenigsberg, J. P. Lockwood, M. L. Tuttle, and G. N. Wagner (1987), The 1986 Lake Nyos gas disaster in Cameroon, West-Africa, Science, 236(4798), $169-175$.

Kocsis, O., H. Prandke, A. Stips, A. Simon, and A. Wüest (1999), Comparison of dissipation of turbulent kinetic energy determined from shear and temperature microstructure, J. Mar. Syst., 21, 61-84.

Komorowski, J. C., et al. (2004), The January 2002 flank eruption of Nyiragongo volcano (Democratic Republic of Congo): Chronology, evidence for a tectonic rift trigger, and impact of lava flows on the city of Goma, Acta Vulcanol., 14/15, 27-62.

Krajick, K. (2003), Efforts to tame second African "Killer Lake" begin, Science, 299, 805.

Lorke, A., K. Tietze, M. Halbwachs, and A. Wüest (2004), Response of Lake Kivu stratification to lava inflow and climate warming, Limnol. Oceanogr., 49(3), 778-783.

Marshall, B. E. (1991), The impact of the introduced sardine Limnothrissa miodon on the ecology of Lake Kariba, Biol. Conserv., 55, 151-165.

Matzner, R. A. (2001), Dictionary of Geophysics, Astrophysics and Astronomy, pp. 85-86, CRC Press, Boca Raton, Fla.

Newman, F. C. (1976), Temperature steps in Lake Kivu: A bottom heated saline lake, J. Phys. Oceanogr., 6, 157163.

Osborn, T. R. (1980), Estimates of the local rate of vertical diffusion from dissipation measurements, J. Phys. Oceanogr., 10, 83-89.

Pollack, H. N., S. J. Hurter, and J. R. Johnson (1993), Heat flow from the Earth's interior: Analysis of the global data set, Rev. Geophys., 31(3), 267-280. 
Reichert, P. (1994), AQUASIM-A tool for simulation and data analysis of aquatic systems, Water Sci. Technol., 30(2), 21-30.

Schmid, M., A. Lorke, C. Dinkel, G. Tanyileke, and A. Wüest (2004a), Double-diffusive convection in Lake Nyos, Cameroon, Deep Sea Res., Part I, 51, 1097-1111.

Schmid, M., K. Tietze, M. Halbwachs, A. Lorke, D. McGinnis, and A. Wüest (2004b), How hazardous is the gas accumulation in Lake Kivu? Arguments for a risk assessment in light of the Nyiragongo Volcano eruption of 2002, Acta Vulcanol., $14 / 15,115-121$.

Schoell, M., K. Tietze, and S. M. Schoberth (1988), Origin of methane in Lake Kivu (East-Central Africa), Chem. Geol., 71, 257-265.

Sigurdsson, H., J. D. Devine, F. M. Tchoua, T. S. Presser, M. K. W. Pringle, and W. C. Evans (1987), Origin of the lethal gas burst from Lake Monoun, Cameroun, J. Volcanol. Geotherm. Res., 31(1-2), 1-16.

Sigvaldason, G. E. (1989), International Conference on Lake Nyos Disaster, Yaounde, Cameroon 16-20 March, 1987Conclusions and recommendations, J. Volcanol. Geotherm. Res., 39(2-3), 97-107.
Stoffers, P., and R. E. Hecky (1978), Late Pleistocene-Holocene evolution of the Kivu-Tanganyika Basin, Spec. Publ. Int. Assoc. Sedimentol., 2, 43-55.

Tedesco, D. (2004), 1995 Nyiragongo and Nyamulagira activity in the Virunga National Park: A volcanic crisis, Acto Vulcanol., 14/15, 149-156.

Tietze, K. (1978), Geophysikalische Untersuchung des Kivusees und seiner ungewöhnlichen Methangaslagerstätte-Schichtung, Dynamik und Gasgehalt des Seewassers, Ph.D. thesis, Christian-Albrechts-Univ., Kiel, Germany.

Turner, J. S. (1965), The coupled turbulent transports of salt and heat across a sharp density interface, Int. J. Heat Mass Transfer, 8, 759-767.

Turner, J. S. (1973), Buoyancy Effects in Fluids, 368 pp., Cambridge Univ. Press, New York.

Wüest, A., G. Piepke, and J. D. Halfman (1996), Combined effects of dissolved solids and temperature on the density stratification of Lake Malawi, in The Limnology, Climatology and Paleoclimatology of the East African Lakes, edited by T. C. Johnson and E. O. Odada, pp. 183-202, Gordon and Breach, New York. 